\title{
Influenza season in Réunion dominated by influenza $B$ virus circulation associated with numerous cases of severe disease, France, 2014
}

E Brottet (elise.brottet@ars.sante.fr) ${ }^{1}$, D Vandroux², B A Gauzere², E Antok ${ }^{3}$, M C Jaffar-Bandjee $^{4}$, A Michault ${ }^{5}$, L Filleul

1. Cire océan Indien (Cire OI), Institut de Veille Sanitaire (InVS), Saint Denis, Réunion, France

2. Intensive Care Unit, Centre Hospitalier Universitaire, Saint-Denis, Réunion, France

3. Intensive Care Unit, Centre Hospitalier Universitaire, Saint-Pierre, Réunion, France

4. Laboratory of virology, Centre Hospitalier Universitaire, Saint-Denis, Réunion, France

5. Laboratory of Biology, Centre Hospitalier Universitaire, Saint-Pierre, Réunion, France

Brottet E, Vandroux D, Gauzere BA, Antok E, Jaffar-Bandjee MC, Michault A, Filleul L. Influenza season in Réunion dominated by influenza B virus circulation associated with numerous cases of severe disease, France, 2014. Euro Surveill. 2014;19(39): pii=20916. Available online: http://www.eurosurveillance.org/

ViewArticle.aspx?Articleld $=20916$

Article submitted on 15 September 2014 / published on 2 October 2014

The 2014 seasonal influenza in Réunion, a French overseas territory in the southern hemisphere, was dominated by influenza B. Resulting morbidity impacted public health. Relative to the total number of all-cause consultations over the whole season, the rate of acute respiratory infection (ARI) consultations was $6.5 \%$. Severe disease occurred in 32 laboratory-confirmed influenza cases (31.7 per 100,000 ARI consultations), 16 with influenza $B$. The observed disease dynamics could present a potential scenario for the next European influenza season.

Réunion is a French overseas territory located in the southern hemisphere between Madagascar and Mauritius in the Indian Ocean. On this island, influenza is monitored through a sentinel practitioner network [1]. Influenza activity generally increases during the austral winter, corresponding to summer in Europe. At the end of May 2014 the proportion of general practitioners' (GP) consultations for acute respiratory infections (ARI) relative to all-cause consultations increased, signalling the beginning of the influenza season. We describe the characteristics of the epidemic.

\section{Surveillance of influenza in Réunion}

Influenza surveillance sentinel network In Réunion, 56 general practitioners (GPs) and two paediatricians (comprising all together $7.2 \%$ of the total GPs on the island) participate in the influenza surveillance sentinel network. Activities of the sentinel GPs represent $4.9 \%$ of total activities of all GPs on the island. They report on a weekly basis the total number of all-cause and acute respiratory infections (ARI) consultations, with ARI defined as a sudden onset of fever $\left(\geq 38^{\circ} \mathrm{C}\right)$ and cough, which are associated or not with other symptoms, such as for example breathing difficulty or headache [2].
In addition to the weekly proportion of ARI among sentinel consultations, a weekly estimated number of ARI consultations is extrapolated from the total number of consultations in Réunion, which is itself derived from health insurance data [3].

Furthermore, every physician of the sentinel network collects a nasal swab from the first two patients of the week who present with ARI symptoms since less than three days. All swabs are analysed by the hospital laboratory by reverse transcription-polymerase chain reaction (RT-PCR) for influenza $A$, influenza $A\left(\mathrm{H}_{1} \mathrm{~N}_{1}\right)$ pdmog and influenza $B$ viruses. In a second step, a subset of the isolates that are positive for influenza $A$, but not $\mathrm{H}_{1} \mathrm{~N}_{1}$ are tested for $\mathrm{H}_{3} \mathrm{~N}_{2}$ by the national influenza centre.

Reporting of cases with severe influenza In addition to the primary healthcare surveillance, all severe influenza cases defined as patients with a laboratory-confirmed influenza infection (positive RT-PCR for influenza virus) admitted for more than 24 hours to an intensive care unit (ICU) are reported by clinicians through a standardised form. Demographic and clinical data are collected as well as risk factors/comorbidities and vaccination status. All the ICUs (adults and paediatrics) present on the island $(n=4)$, which cover the total population, participate in this surveillance and swab all patients with severe ARI.

Confirmation of laboratory findings and genetic and antigenic characterisation Every year, a randomly-selected sample is sent to the national influenza centre in mainland France for confirmation and genetic and antigenic characterisation. In 2014, this sample consisted of 11 swabs from sentinel surveillance (2\%) and 15 swabs (47\%) from intensive care unit (ICU). 
Analysis of epidemics relative to prior

influenza seasons

Epidemic periods are defined as an increase of the number of ARI consultations above the mean of such consultations during the same periods in the previous years (the 2010-2013 mean was taken for comparison to 2014) and an increase of the positive rate for influenza viruses (proportion of persons testing positive for influenza virus among all persons tested for influenza) superior to $50 \%$.

Historical data from 2010 to 2014 , which had been collected by the influenza surveillance system annually, including during epidemic periods, were compared. For each year, including epidemic periods, the number of cases with severe influenza relative to the numbers of ARI consultations was calculated both for the year in question and for the year's respective epidemic periods. The influenza surveillance system remained the same during the five years studied in terms of population covered and sampling protocol.

\section{Influenza epidemic in 2014 in Réunion}

\section{Description of the epidemic}

The proportion of ARI among the all-cause GP consultations increased at the end of May 2014 (week 22) and reached $9.3 \%$ in the first week of July (week 27). For this week, the estimated number of consultations due to ARI was 11,800 (Figure). Between the beginning of the epidemic on 26 May 2014 (week 22) and the end on 27 July 2014 (week 30), the number of patients with ARI who consulted a physician was estimated at 69,500 , which represents a cumulative rate of $6.5 \%$ $(69,500 / 1,070,000)$ of total consultations at GPs.
During the epidemic, $62 \%(169 / 273)$ of samples were positive for influenza. Among the 169 identified viruses, 118 (70\%) were influenza B, 44 (26\%) influenza $A\left(\mathrm{H}_{1} \mathrm{~N}_{1}\right)$ pdmog and seven (4\%) influenza $A$ but not $\mathrm{H}_{1} \mathrm{~N}_{1}$. In a second step, a subset of influenza $A$ not $\mathrm{H}_{1} \mathrm{~N}_{1}$ isolates were all confirmed as influenza $\mathrm{A}\left(\mathrm{H}_{3} \mathrm{~N}_{2}\right)$ viruses. From the sample of genetically and antigenically characterised viruses $(n=26), 13$ influenza $A$ viruses were $A\left(\mathrm{H}_{1} \mathrm{~N}_{1}\right)$ pdmog and 10 influenza $B$ viruses belonged to the Yamagata lineage. These viruses were of the same strains than those targeted by the 2014 seasonal vaccine for the southern hemisphere $(B /$ Massachusetts/2/2012 for the influenza $B$ viruses and A/California/7/2009 for influenza A).

\section{Characteristics of laboratory-confirmed} influenza cases with severe disease

Among the 32 cases identified with severe disease in 2014 (Table 1), 16 were infected with influenza $B$ virus, 13 with $A\left(\mathrm{H}_{1} \mathrm{~N}_{1}\right)$ pdmog virus and three with $A\left(\mathrm{H}_{3} \mathrm{~N}_{2}\right)$ virus. Patients with influenza $B$ were older than those affected by $A\left(\mathrm{H}_{1} \mathrm{~N}_{1}\right)$ pdmog virus (mean of 58 years vs 42 years respectively, $p=0.03$ ). Five of 13 influenza $A\left(\mathrm{H}_{1} \mathrm{~N}_{1}\right)$ pdmog cases had no comorbidities compared to one of 16 influenza B cases. Most $(n=24)$ of the cases with severe disease who presented at least one risk factor/comorbidity were not vaccinated, although the information was not available for four of 32 total patients. Among the 32 cases with severe influenza, nine deaths occurred including four infected with influenza $B$ virus and five with influenza $A\left(\mathrm{H}_{1} \mathrm{~N}_{1}\right)$ pdmog virus (including two patients with no risk factors).

\section{FIGURE}

Weekly estimation of acute respiratory infections consultations and number of samples positive for influenza viruses, Réunion, France, 2014

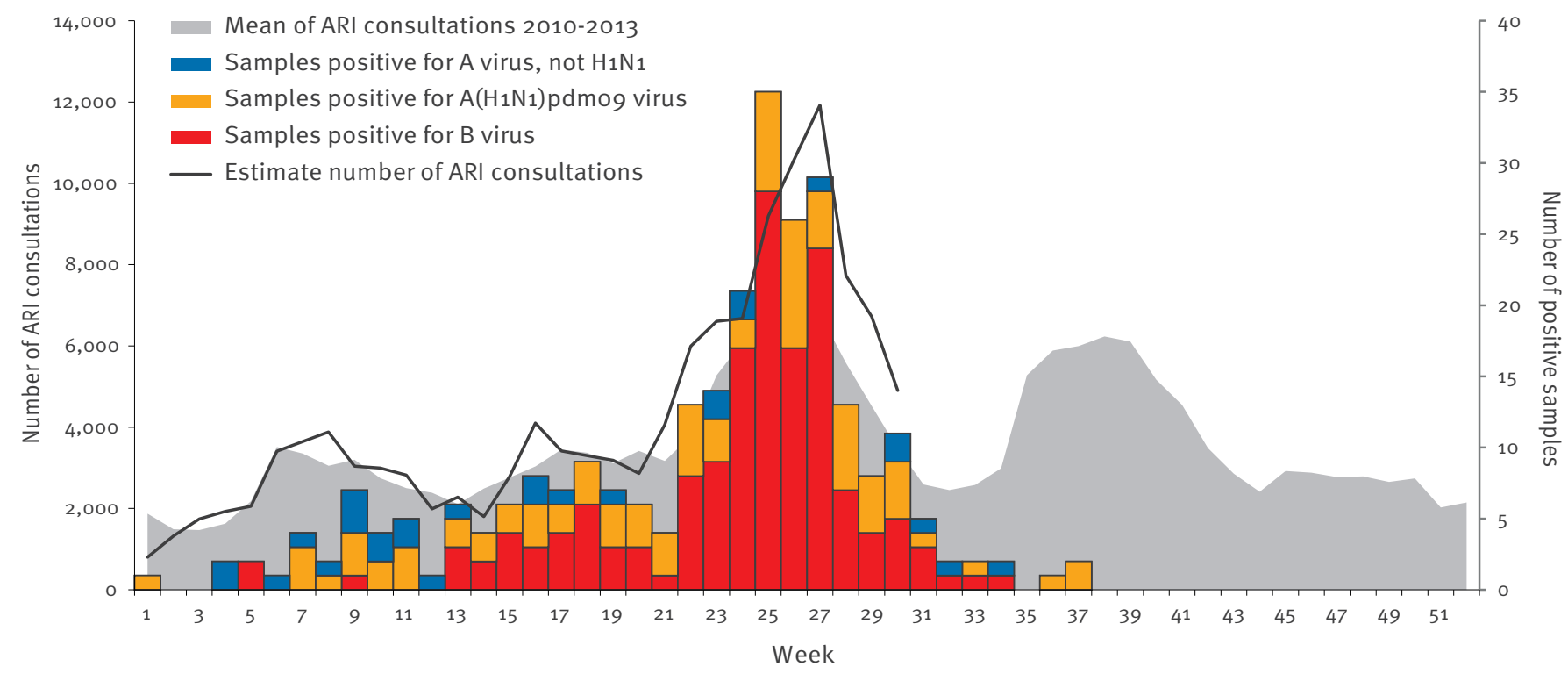

ARI: acute respiratory infection. 
TABLE 1

Characteristics of cases with severe influenza, Réunion, France, 2014 (n=32)

\begin{tabular}{|c|c|c|c|c|}
\hline \multirow[b]{2}{*}{ Characteristic } & \multicolumn{3}{|c|}{ Influenza virus type } & \multirow{2}{*}{$\begin{array}{c}\text { Total } \\
(n=32)\end{array}$} \\
\hline & $\begin{array}{c}B \\
(n=16)\end{array}$ & $\begin{array}{c}\mathrm{A}\left(\mathrm{H}_{1} \mathrm{~N}_{1}\right) \mathrm{pdm} \text { mo9 } \\
(\mathrm{n}=13)\end{array}$ & $\begin{array}{c}\text { A non- }-\mathrm{H}_{1} \mathrm{~N}_{1} / \mathrm{A}_{\left(\mathrm{H}_{3} \mathrm{~N}_{2}\right)^{\mathrm{a}}} \\
(\mathrm{n}=3)\end{array}$ & \\
\hline \multicolumn{5}{|c|}{ 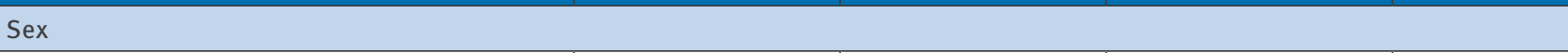 } \\
\hline Male/female & $12 / 4$ & $6 / 7$ & $3 / 0$ & $21 / 11$ \\
\hline \multicolumn{5}{|l|}{ Age } \\
\hline Mean age in years (range) & $58(5-82)$ & $42(1-71)$ & $53(19-76)$ & $51(1-82)$ \\
\hline \multicolumn{5}{|l|}{ Age groups in years } \\
\hline $0-4$ & o & 1 & o & 1 \\
\hline $5-14$ & 1 & 1 & 0 & 2 \\
\hline $15-64$ & 10 & 8 & 2 & 20 \\
\hline$\geq 65$ & 5 & 3 & 1 & 9 \\
\hline \multicolumn{5}{|l|}{ Risk factors/comorbidities } \\
\hline Respiratory disease & 7 & 3 & 0 & 10 \\
\hline Diabetes & 2 & 4 & 2 & 8 \\
\hline Cardiac disease & 5 & 4 & 2 & 11 \\
\hline Pregnancy & 0 & 2 & 0 & 2 \\
\hline Hepatic disease & 2 & 0 & 0 & 2 \\
\hline None & 1 & 5 & 0 & 6 \\
\hline More than one risk factor/comorbidities & 8 & 4 & 2 & 14 \\
\hline \multicolumn{5}{|l|}{ Indicators or signs of severity } \\
\hline Respiratory assistance & 13 & 8 & 2 & 23 \\
\hline With acute respiratory distress syndrome & 10 & 7 & 1 & 18 \\
\hline With extracorporeal membrane oxygenation & 0 & 5 & o & 5 \\
\hline Death & 4 & 5 & 0 & 9 \\
\hline \multicolumn{5}{|l|}{ Influenza vaccination } \\
\hline Vaccinated & 0 & 0 & 0 & 0 \\
\hline Unvaccinated & 15 & 11 & 2 & 28 \\
\hline Not specified & 1 & 2 & 1 & 4 \\
\hline
\end{tabular}

a The influenza A subtype is not $\mathrm{H}_{1} \mathrm{~N}_{1}$ and likely to be $\mathrm{A}\left(\mathrm{H}_{3} \mathrm{~N}_{2}\right)$.

\section{TABLE 2}

Indicators of influenza surveillance, Réunion, France, 2010-2014

\begin{tabular}{|c|c|c|c|c|c|c|}
\hline \multicolumn{2}{|l|}{ Year } & 2010 & 2011 & 2012 & 2013 & 2014 \\
\hline \multicolumn{2}{|c|}{ Epidemic period (week numbers) } & $35-45$ & $22-29$ & $23-30$ and $35-39$ & $23-30$ & $22-30$ \\
\hline \multicolumn{2}{|c|}{ Predominant influenza viruses } & $\mathrm{A}\left(\mathrm{H}_{1} \mathrm{~N}_{1}\right) \mathrm{pdmog}$ & $\mathrm{A}\left(\mathrm{H}_{3} \mathrm{~N}_{2}\right)$ & $A\left(\mathrm{H}_{3} \mathrm{~N}_{2}\right)+\mathrm{B}$ & $\mathrm{A}\left(\mathrm{H}_{1} \mathrm{~N}_{1}\right) \mathrm{pdmog}$ & B \\
\hline \multirow{2}{*}{$\begin{array}{l}\text { Number of laboratory- } \\
\text { confirmed influenza cases } \\
\text { with severe disease }\end{array}$} & Annual & 14 & 8 & 9 & 18 & 32 \\
\hline & During epidemic period & 12 & 5 & 4 & 15 & 22 \\
\hline \multirow{2}{*}{ Number of deaths in ICU } & Annual & 7 & 1 & 4 & 7 & 9 \\
\hline & During epidemic period & 7 & 0 & 1 & 7 & 7 \\
\hline \multicolumn{2}{|c|}{ Estimated number of ARI consultations during epidemic period } & 74,000 & 50,300 & 97,000 & 53,400 & 69,500 \\
\hline \multirow{2}{*}{$\begin{array}{l}\text { Incidence rate of cases with } \\
\text { severe influenza for } 100,000 \\
\text { ARI consultations }\end{array}$} & Annual $^{\mathrm{a}}$ & 18.9 & 15.9 & 9.3 & 33.7 & 46.0 \\
\hline & During epidemic period ${ }^{b}$ & 16.2 & 9.9 & 4.1 & 28.1 & 31.7 \\
\hline
\end{tabular}

ARI: acute respiratory infection; ICU: intensive care unit.

a The annual rate $=$ annual number of cases with severe disease/estimated number of ARI consultations during the epidemic period that year.

b The rate during the epidemic $=$ number of cases with severe disease during the epidemic period/estimated number of ARI consultations during the epidemic period. 
Comparison of the 2014 epidemic to previous influenza seasons

The estimated annual incidence of cases with severe influenza observed in Réunion in 2014 is the highest since 2010, with 46 cases per 100,000 consultations for ARI (Table 2).

\section{Discussion}

It is the first time since 2009 (date of the set-up of virological surveillance) that an influenza epidemic is mainly due to influenza B virus in Réunion.

Compared to the four past years, the 2014 seasonal influenza outbreak on the island has had a higher impact on public health in terms of related morbidity and the incidence of cases in ICU presenting with severe disease [4], which is the highest since 2010. This result cannot be linked to a surveillance bias as we have had the same complete monitoring records since 2010 with the participation of all ICUs in Réunion. Furthermore, during the last five influenza seasons, we contacted ICU doctors weekly to obtain information about cases with severe influenza.

The characterisation of viruses circulating this season showed that influenza $B$ and influenza $A\left(\mathrm{H}_{1} \mathrm{~N}_{1}\right)$ pdmog viruses were of the strains covered by the seasonal influenza vaccine for the southern hemisphere in 2014 [5]. Furthermore, most patients in ICU with risk factors were not vaccinated. The last estimation of the immunisation coverage for influenza among vulnerable people targeted by vaccination in 2013 was $39.7 \%$ in Réunion vs $50.1 \%$ in mainland France [6].

The influenza pattern and the types of viruses observed in Réunion are similar to those of other countries in the Indian Ocean this year, specifically Madagascar where influenza B virus Yamagata lineage was identified in June and July. In contrast, in the Pacific area (Australia, New Zealand) and South America, influenza A viruses predominated [7].

To our knowledge, few reports have described cases of severe disease due to influenza B virus [8]. Our results, presenting the individual characteristics of cases of severe disease, in clinical and virological terms, contribute to an enhanced knowledge of the burden of influenza $B$. The cases with most severe influenza in ICU infected by influenza $B$ virus were not vaccinated, and had at least one risk factor/comorbidity, particularly respiratory disease. Moreover, these patients were older than patients infected with $\mathrm{A}\left(\mathrm{H}_{1} \mathrm{~N}_{1}\right)$ pdmog virus.

Despite the fact that Réunion represents a small area in the southern hemisphere, the typical pattern of influenza outbreaks has already been shown to be of interest for Europe [2]. The epidemic features observed in Réunion during the influenza season 2014 could be similar in the upcoming 2014/15 season in Europe $[9,10]$. An increase of influenza immunisation coverage among targeted groups could prevent a number of cases of severe illness. Promoting specific awareness and information on vaccination in the population for which influenza vaccination is recommended could avoid severe cases in ICU in mainland France or Europe for the $2014 / 15$ influenza season.

\section{Acknowledgements}

We are thankful to all the sentinel network practitioners, the practitioners of the intensive care unit and biological laboratories. We want also to thank Emmanuel Belchior and Isabelle Bonmarin for French influenza expertise and reviewing of this publication.

\section{Conflict of interest}

None declared.

\section{Authors' contributions}

All authors contributed to the interpretation of the results, the revision of the draft manuscript and approved the final version. EB conducted the data analysis and wrote the manuscript; DV, BAG and EA was involved in the data collection in ICU; MCJB was responsible for the viral laboratory analyses; AM was involved in the laboratory analysis; LF was involved in the design of the influenza surveillance system and participated in the writing of the manuscript.

\section{References}

1. D’Ortenzio E, Do C, Renault P, Weber F, Filleul L. Enhanced influenza surveillance on Réunion Island (southern hemisphere) in the context of the emergence of influenza $\mathrm{A}\left(\mathrm{H}_{1} \mathrm{~N} 1\right) \mathrm{v}$. Euro Surveill. 2009;14(23): pii=19239.

2. Filleul L, Brottet E, Gauzere BA, Winer A, Vandroux D, Michault $A$, et al. Réunion, a sentinel territory for influenza surveillance in Europe. Euro Surveill. 2012;17(27):pii= 20212.

3. Renault P, D’Ortenzio E, Kermarec F, Filleul L. Pandemic influenza 2009 on Réunion Island: A mild wave linked to a low reproduction number. Version 2. PLoS Curr. 2010 Jan 19 [revised 2010 Jan 19];2:RRN1145.

4. Vandroux D, Brottet E, Ursulet L, Angue M, Jabot J, Filleul L, et al. New patterns of $\mathrm{A}\left(\mathrm{H}_{1} \mathrm{~N}_{1}\right)$ pdmog influenza in the Southern Hemisphere. Intensive Care Med. 2014;40(1):131-2. http:// dx.doi.org/10.1007/s00134-013-3143-1

5. World Health Organization (WHO). Recommended composition of influenza virus vaccines for use in the 2014 southern hemisphere influenza season. Geneva:WHO;26 Sep 2013 (revised 11 October 2013).

6. Brottet E, Ristor B, Simoes J, Polycarpe D, Filleul L. Couverture vaccinale antigrippale à la Réunion de 2009 à 2013. BVS océan Indien. 2014;22:11-12. French. Available from: http:// www.invs.sante.fr/fr/Publications-et-outils/Bulletin-de-veillesanitaire/Tous-les-numeros/Ocean-indien-Reunion-Mayotte/ Bulletin-de-veille-sanitaire-ocean-Indien.-N-22-Juin-2014

7. World Health Organization (WHO). FluNet. Influenza Laboratory Surveillance Information by the Global Influenza Surveillance and Response System (GISRS). Geneva: WHO. Available from: http://gamapserver.who.int/gareports/Default. aspx?ReportNo=1

8. 8. Paul Glezen W, Schmier JK, Kuehn CM, Ryan KJ, Oxford J. The burden of influenza B: a structured literature review. Am Public Health. 2013;103(3):e43-51. http://dx.doi.org/10.2105/ AJPH.2012.301137

9. Cottrell SL, Moore C, Dexter L, Thomas DR, Salmon RL. Unusually high impact of influenza B during the early 2012 2013 influenza season in Wales--epidemiology and clinical analysis of the first 100 cases. Influenza Other Respir Viruses. 2013;7(6):1013-6. http://dx.doi.org/10.1111/irv.12151

10. Mook P, Ellis J, Watson JM, Thompson C, Zambon M, McMenamin J, et al. Public health implications of influenza B outbreaks in closed settings in the United Kingdom in the $2007 / 08$ influenza season. Euro Surveill. 2008;13(38):pii=18986. 